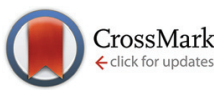

Cite this: Food Funct., 2014, 5, 3132

\title{
Bioactivity and phenolic composition from natural fermented table olives
}

\author{
Ricardo Malheiro, ${ }^{\text {a,b }}$ Patrícia Mendes, ${ }^{a}$ Fátima Fernandes, ${ }^{a}$ Nuno Rodrigues, ${ }^{a}$ \\ Albino Bento ${ }^{a}$ and José Alberto Pereira*a
}

\begin{abstract}
In the present work, the phenolic composition, and antioxidant and antimicrobial properties of twentyfour samples of naturally fermented table olives from the northeast of Portugal were evaluated. The analysis of phenolic composition was performed by HPLC/DAD, and ten compounds were identified, hydroxytyrosol, verbascoside derivate and hydroxytyrosol glycol being the most abundant. Total phenolic content varied between 2.37 and $64.17 \mathrm{\mu g} \mathrm{mg}^{-1}$ of extract. The $\mathrm{IC}_{50}$ values from the antioxidant activity methods tested varied between 0.30 and $1.66 \mathrm{mg} \mathrm{mL}^{-1}$ for reducing power, and between 0.13 and $0.83 \mathrm{mg} \mathrm{mL}^{-1}$ for DPPH. The results obtained in the antioxidant activity were extremely significantly correlated with the main phenolic compounds as well as with the total phenolic content. A principal component analysis allowed grouping the samples according to their phenolic composition and antioxidant potential. Table olive extracts were able to inhibit some pathogenic microorganisms, mainly Gram-positive bacteria. Higher antimicrobial inhibition was recorded in the extracts rich in phenolic compounds and higher antioxidant potential.
\end{abstract}

Received 24th June 2014, Accepted 7th September 2014

DOI: $10.1039 / \mathrm{c} 4 \mathrm{fo} 00560 \mathrm{k}$

www.rsc.org/foodfunction

\section{Introduction}

Table olives are among the most popular fermented food products worldwide, and are an important ingredient of the Mediterranean diet. In the last two decades, according to the data released by the International Olive Council (IOC), the worldwide consumption of table olives increased continuously, a consumption of 2668000 tonnes being predicted during the 2013/2014 season. ${ }^{1}$ Such popularity is related with their sensorial characteristics and health promoting properties. The beneficial and healthy aspects attributed to table olives are mainly related with their fatty acid composition, and minor compound content, namely tocopherols, sterols and phenolic compounds. $^{2-4}$

The olive fruits' phenolic composition is well studied and documented. According to Amiot et al. ${ }^{5}$ phenolic compounds in olive fruits account for approximately 1 to $2 \%$ of the fresh drupe. Oleuropein is the main phenolic compound found in green unprocessed olives; it is a 3,4-dihydroxy-phenylethanol ester with a $\beta$-glucosylated elenolic acid, which is responsible

\footnotetext{
${ }^{a}$ Mountain Research Centre (CIMO), School of Agriculture, Polytechnic Institute of Bragança, Campus de Santa Apolónia, Apartado 1172, 5301-855 Bragança, Portugal. E-mail: rmalheiro@ipb.pt, jpereira@ipb.pt; Fax:+351 273325405, +351 273325405; Tel: $+351273303344,+351273303277$

${ }^{b}$ REQUIMTE/Laboratório de Bromatologia e Hidrologia, Faculdade de Farmácia, Universidade do Porto, Rua Jorge Viterbo Ferreira, 228, 4050-313 Porto, Portugal
}

for the natural bitterness of the fruit. During the physiological development of the fruit, oleuropein content decreases drastically, there being observed a prevalence of hydroxytyrosol and its derivates in mature olives. These compounds are associated with diversified bioactive properties, acting as antioxidants ${ }^{6}$ and as antimicrobial agents. ${ }^{7}$ The phenolic composition of olive fruits and table olives is affected by several factors that also change the bioactivity of table olives. Olive cultivar, ${ }^{8,9}$ olive maturation, ${ }^{10}$ and the technological process applied to turn olives edible ${ }^{11,12}$ are among the issues that most affect olives and table olives' phenolic composition. In order to achieve edibility, olives need to undergo a technological process. In the international market there are three representative kinds of table olives: Spanish-style green olives in brine, Greek-style naturally black olives in brine, and Californian black ripe olives. Among the three technological processes, table olives from the Californian-style are those which present lower phenolic content, while Spanish- and Greek-style methods provide higher and appreciable amounts of phenolic compounds. ${ }^{13}$

In Portugal, Trás-os-Montes (north-eastern region of Portugal) is the second most important olives producing region. In this region table olives are mainly produced by natural fermentation, being an important socio-economic aspect for producers. The characterization of these table olives is being carried out, and the phenolic composition and bioactivity of the natural fermented table olives from Trás-os-Montes have never been assessed before. 
In the present work the main objective is to characterize the phenolic composition of natural fermented table olives from the Trás-os-Montes region (northeast of Portugal) as well to study their antioxidant activity and antimicrobial properties. Phenolics from table olives were obtained by aqueous extraction and their profile was determined by HPLC-DAD (highperformance liquid chromatography with a diode array detector). The antioxidant activity was evaluated by the reducing power and scavenging effects on DPPH radical assays and the obtained data were correlated with the amount of phenolics found in each sample. The antimicrobial activity was screened using Gram-positive (Bacillus subtilis, Bacillus cereus, Staphylococcus epidermidis, Staphylococcus aureus) and Gram-negative bacteria (Escherichia coli, Pseudomonas aeruginosa).

\section{Results and discussion}

\section{Phenolic profile of natural fermented table olives}

The phenolic composition of 24 samples of natural fermented table olives from the Trás-os-Montes region (detailed information about samples in Table 1) was studied and the obtained profile is reported in Table 2. Among the 24 samples, ten individual phenolic compounds were found (Fig. 1 and 2), namely, three phenolic alcohols (hydroxytyrosol glycol, hydroxytyrosol, and tyrosol), three flavones (luteolin 7-O-glucoside, apigenin 7-O-glucoside, and apigenin), two hydroxycinnamic acids (verbascoside derivate and verbascoside), one phenolic acid (5-O-caffeoylquinic acid), and one flavonol (rutin). The results revealed differences among samples, both in compounds identified as well as in their amounts. Hydroxytyrosol was the most abundant phenolic compound identified in the table olives (average value of $10.76 \mu \mathrm{g} \mathrm{mg}^{-1}$ of extract), followed by verbascoside derivate (average of $3.26 \mu \mathrm{g} \mathrm{mg}^{-1}$ ), and hydroxytyrosol glycol (average of $3.13 \mu \mathrm{g} \mathrm{mg}^{-1}$ ). Hydroxytyrosol was present in all the 24 samples studied and its content ranged between $0.63 \mu \mathrm{g} \mathrm{mg}^{-1}$ (sample 24) and $34.17 \mu \mathrm{g} \mathrm{mg}^{-1}$ (sample 17). This compound is reported as the main phenolic compound in processed table olives. ${ }^{11,12}$ Hydroxytyrosol could be formed, in part, during olive maturation due to the action of $\beta$-glucosidases, esterases and polyphenol oxidase, but also during fermentation of olives. Its formation is due to the hydrolytic cleavage of the ester bond on oleuropein, ${ }^{14}$ explaining the absence of oleuropein in the final table olives. During fermentation, oleuropein, the main phenolic compound present in unprocessed olive fruits, is converted into several oleuropein derivates, including hydroxytyrosol. This high content in hydroxytyrosol may confer important properties to table olives since to this compound are ascribed several bioactive properties: antioxidant activity, ${ }^{15,16}$ reduction in atherosclerosis development, ${ }^{17}$ reduction in the risk of thrombosis, ${ }^{18}$ reduction in oxidative stress, ${ }^{19}$ reduction in the risk of heart disease, ${ }^{20}$ antimicrobial properties, ${ }^{7}$ and anti-cancer properties. ${ }^{21}$

Hydroxytyrosol glycol (3,4-dihydroxyphenylglycol) was also present in the 24 table olive samples. Its content varied between $0.29 \mu \mathrm{g} \mathrm{mg}^{-1}$ (sample 15) and $16.56 \mu \mathrm{g} \mathrm{mg}^{-1}$ (sample 22). This $\mathrm{C}_{6}-\mathrm{C}_{2}$ phenolic compound is not only present in table olives but also in unprocessed olives, olive oil and olive mill waste waters. ${ }^{22-24}$ This compound exerts an even higher antioxidant activity than hydroxytyrosol. ${ }^{25}$

Verbascoside derivate was absent in only one sample (sample 16), and varied between $0.05 \mu \mathrm{g} \mathrm{mg}^{-1}$ (sample 16) and

Table 1 Basic characteristics of samples

\begin{tabular}{|c|c|c|c|c|}
\hline Sample & Region & Cultivar & Type of olives $^{a}$ & Pulp/stone ratio \\
\hline 1 & Mirandela & Cobrançosa & Black olives & $5.60 \pm 0.78$ \\
\hline 2 & Mirandela & Cobrançosa & Green olives & $3.87 \pm 0.45$ \\
\hline 3 & Mirandela & Cobrançosa & Olives turning color & $5.39 \pm 0.52$ \\
\hline 4 & Mirandela & Cobrançosa & Green olives & $4.74 \pm 0.73$ \\
\hline 5 & Mirandela & Cobrançosa & Olives turning color & $5.40 \pm 0.51$ \\
\hline 6 & Mirandela & Cobrançosa & Olives turning color & $4.77 \pm 0.79$ \\
\hline 7 & Valpaços & Cobrançosa & Green olives & $3.30 \pm 0.67$ \\
\hline 8 & Mirandela & Cobrançosa & Green olives & $4.63 \pm 0.57$ \\
\hline 9 & Valpaços & Cobrançosa & Olives turning color & $5.41 \pm 0.60$ \\
\hline 10 & Valpaços & Cobrançosa & Green olives & $4.76 \pm 0.64$ \\
\hline 11 & Valpaços & Cobrançosa & Olives turning color & $5.27 \pm 0.77$ \\
\hline 12 & Valpaços & Cobrancosa & Green olives & $4.96 \pm 0.57$ \\
\hline 13 & Valpaços & Cobrançosa & Olives turning color & $5.31 \pm 0.51$ \\
\hline 14 & Mirandela & Cobrancosa & Olives turning color & $4.87 \pm 0.66$ \\
\hline 15 & Valpaços & Negrinha de Freixo & Olives turning color & $5.38 \pm 1.11$ \\
\hline 16 & Mirandela & Cobrançosa & Olives turning color & $5.62 \pm 0.68$ \\
\hline 17 & Moncorvo & Negrinha de Freixo & Green olives & $5.80 \pm 0.76$ \\
\hline 18 & Moncorvo & Negrinha de Freixo & Green olives & $4.80 \pm 0.58$ \\
\hline 19 & Valpaços & Cobrançosa & Olives turning color & $5.20 \pm 0.86$ \\
\hline 20 & Mirandela & Cobrançosa & Black olives & $5.40 \pm 0.78$ \\
\hline 21 & Mirandela & Cobrancosa & Green olives & $6.72 \pm 1.31$ \\
\hline 22 & Mirandela & Cobrançosa & Olives turning color & $5.32 \pm 0.73$ \\
\hline 23 & Mirandela & Cobrançosa & Olives turning color & $4.65 \pm 0.69$ \\
\hline 24 & Mirandela & Cobrançosa & Olives turning color & $5.44 \pm 0.85$ \\
\hline
\end{tabular}

${ }^{a}$ Classification according to the Trade Standard Applying to Table Olives (International Olive Council) COI/OT/NC no. 1 December 2004. 


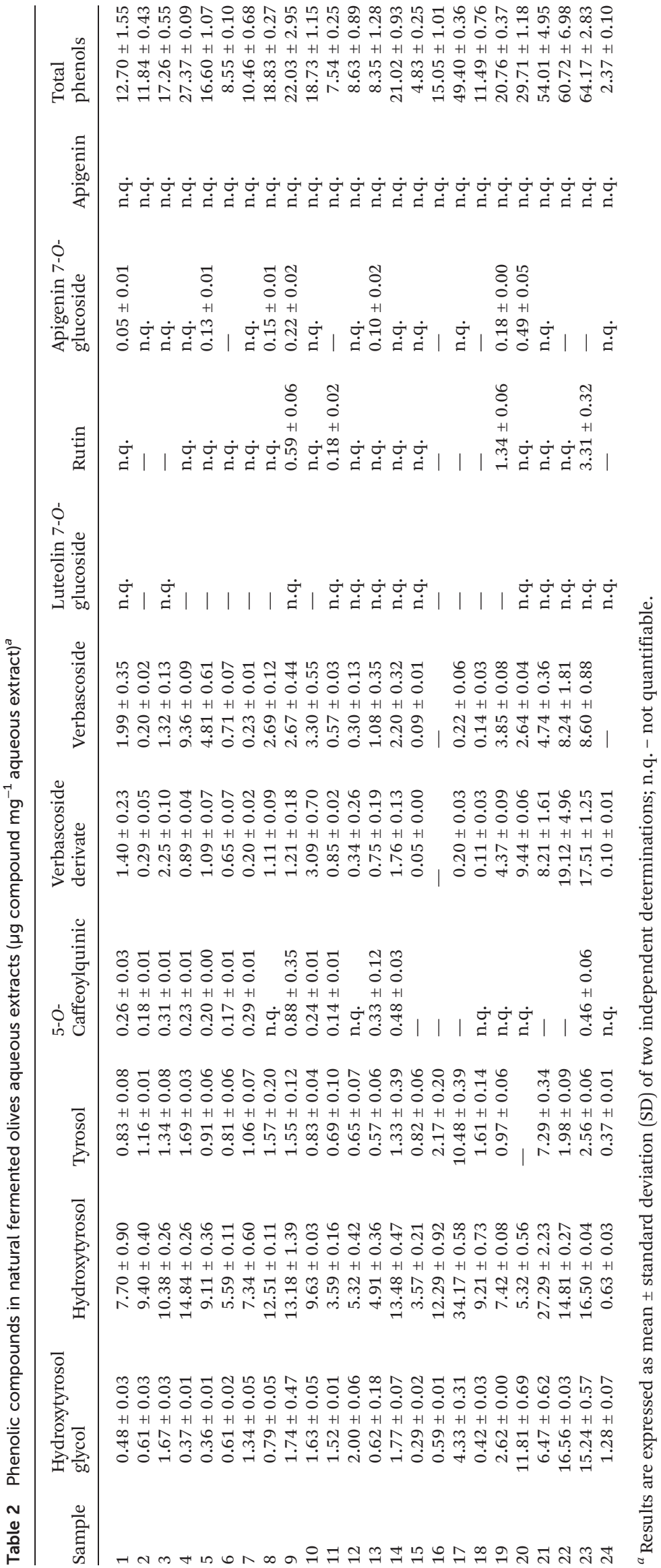




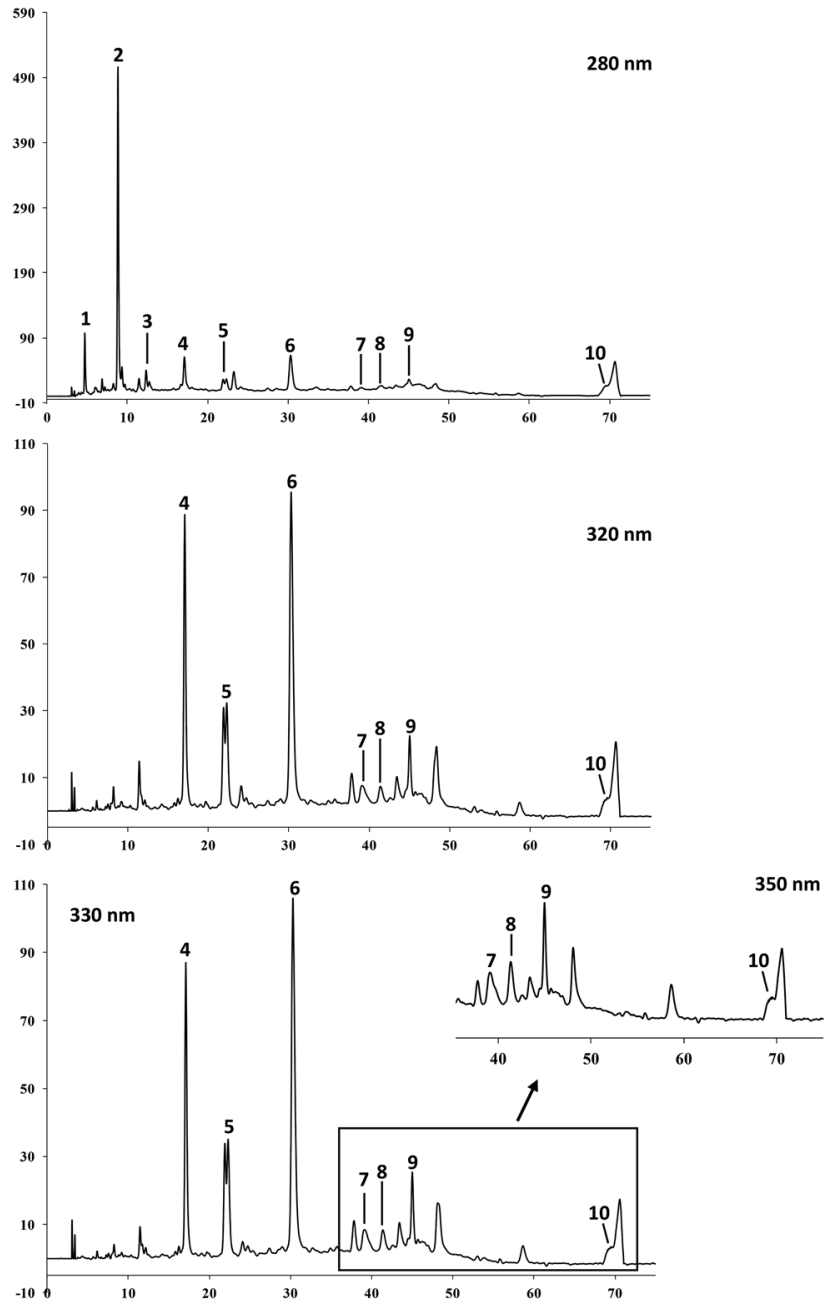

Fig. 1 HPLC-DAD of phenolic compounds in natural fermented olives. Detection at 280, 320, 330 and $350 \mathrm{~nm}$. Peaks: (1) hydroxytyrosol glycol; (2) hydroxytyrosol; (3) tyrosol; (4) 5-O-caffeoylquinic acid; (5) verbascoside derivative; (6) verbascoside; (7) luteolin-7-O-glucoside; (8) rutin; (9) apigenin-7-O-glucoside; and (10) apigenin.

$19.12 \mu \mathrm{g} \mathrm{mg}{ }^{-1}$ (sample 22). Verbascoside and tyrosol were present in considerable amounts, with median values of 2.72 and $1.88 \mu \mathrm{g} \mathrm{mg}{ }^{-1}$, respectively. Apigenin 7-O-glucoside, 5-Ocaffeoylquinic acid, and rutin were present in small amounts, being absent or not quantifiable in many samples (Table 2). Luteolin 7-O-glucoside and apigenin were identified in some table olive samples but their amount was below the limit of quantification, thus it is impossible to quantify them.

Concerning total phenol content, they varied between 2.37 $\mu \mathrm{g}$ of total phenol $\mathrm{mg}^{-1}$ of extract (sample 24) and $64.17 \mu \mathrm{g}$ $\mathrm{mg}^{-1}$ (sample 23). Such differences in total phenol content are related mainly with three aspects: (i) olive cultivar; (ii) the maturation stage of the olive fruits at the harvest time; and (iii) the state of the fruits at fermentation. Concerning this last aspect, sometimes prior to fermentation, olive fruits are split lengthwise by cutting into the skin and part of the flesh in order to facilitate brine introduction. This leads to a higher lixiviation of phenolic compounds to the brine, which explains the low content of total phenols observed in samples $6,7,11$, 15 and 24 (in the remaining samples, fruits were fermented as natural as possible).

\section{Antioxidant activity of fermented table olives}

The antioxidant activity of the aqueous extracts of natural fermented table olives was assessed by two different chemical assays: reducing power and scavenging effect on DPPH free radicals. In the first method, the presence of reducers and their capacity to reduce the $\mathrm{Fe}^{3+} /$ ferricyanide complex to the ferrous form is evaluated in table olives. The more greenish or bluish is the test solution, the higher the reducing power displayed by the tested extract. In the second method the antiradical potential of the extracts is evaluated. The loss of absorbance at $517 \mathrm{~nm}$ is indicative of the scavenging capacity, the test solution showing a yellow-transparent coloration instead of the violet color of the blank solution. The higher the loss in absorbance, the higher the presence of natural antioxidants able to scavenge the free radicals of DPPH, indicative of a high antiradical activity.

The results obtained are expressed as $\mathrm{IC}_{50}$ values $(\mathrm{mg}$ $\mathrm{mL}^{-1}$ ) and as the quantity of olive pulp (mg) and are reported in Table 3. In both the methods tested a concentration-dependent activity was observed (Fig. 3). In the table olive extracts high reducing power was observed at low concentrations. The $\mathrm{IC}_{50}$ values varied between $0.30 \mathrm{mg} \mathrm{mL}^{-1}$ and $1.66 \mathrm{mg} \mathrm{mL}^{-1}$ in samples 22 and 18 respectively. Among all samples, sample 24 revealed lower reducing power. For this sample, it was only possible to calculate the $\mathrm{IC}_{25}$ value $\left(2.67 \mathrm{mg} \mathrm{mL}^{-1}\right)$. When $\mathrm{IC}_{50}$ values were converted into the mass of olive pulp, sample 22 reported $5.05 \mathrm{mg}$ while sample 18 reported $27.94 \mathrm{mg}$. Concerning sample 24 , the $\mathrm{IC}_{25}$ value corresponds to $44.86 \mathrm{mg}$ of olive pulp (Table 3).

The results observed in the DPPH method are in accordance with those obtained in the reducing power. Sample 22 reported a lower $\mathrm{IC}_{50}$ value, $0.13 \mathrm{mg} \mathrm{mL}^{-1}$, consequently displaying higher antiradical activity, while sample 18 reported lower activity, reporting though a higher $\mathrm{IC}_{50}$ value, $0.83 \mathrm{mg}$ $\mathrm{mL}^{-1}$. As observed in the reducing power method, for sample 24 it was only possible to calculate the necessary extract concentration to scavenge $25 \%$ of the free radicals of DPPH (1.85 $\mathrm{mg} \mathrm{mL}^{-1}$ ). When $\mathrm{IC}_{50}$ values for the DPPH method were converted into mass of olive pulp, sample 22 reported $2.12 \mathrm{mg}$, sample 18 reported $13.90 \mathrm{mg}$, and sample 24 reported $31.15 \mathrm{mg}$ which correspond to the $\mathrm{IC}_{25}$ value for the same aqueous extract.

Comparatively to other table olives from the northeast of Portugal, natural fermented table olive extracts revealed a similar antioxidant activity to commercial "alcaparras" table olives, ${ }^{26}$ but a higher activity than monocultivar "alcaparras" table olives. ${ }^{8}$ Our results are also comparable to the antioxidant activity of Portuguese table olives from different olive cultivars and processed by different technological treatments. ${ }^{11}$ In fact these authors observed that natural fermented table olives were those who reported higher total phenol content and higher antioxidant activity. Comparatively to 
<smiles>OCC(O)c1ccc(O)c(O)c1</smiles>

Hydroxytyrosol glycol<smiles>OCCc1ccc(O)c(O)c1</smiles>

Hydroxytyrosol<smiles>OCCc1ccc(O)cc1</smiles>

Tyrosol<smiles>O=C(/C=C/c1ccc(O)c(O)c1)OC1CC(O)(C(=O)O)C[C@H](O)[C@H]1O</smiles>

5-O-caffeoylquinic acid<smiles>CCOC1OC(O)C(OC(=O)/C=C/c2ccc(O)c(O)c2)C(OC2OC(C)[C@@H](O)[C@H](O)C2O)C1O</smiles>

Verbascoside<smiles>O=c1cc(-c2ccc(O)c(O)c2)oc2cc(OC3OC(CO)C(O)C(O)C3O)cc(O)c12</smiles>

Luteolin 7-O-glucoside<smiles>O=c1cc(-c2ccc(O)cc2)oc2cc(O)cc(O)c12</smiles>

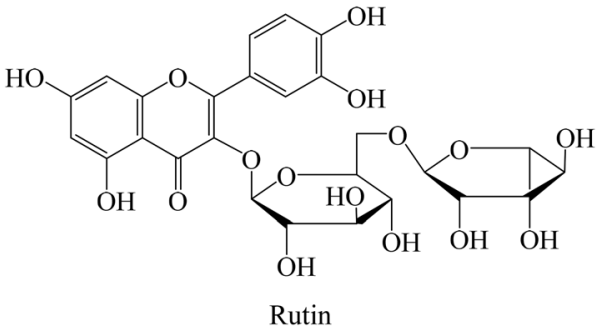<smiles></smiles>

Fig. 2 Chemical structures of the phenolic compounds identified. (1) Hydroxytyrosol glycol; (2) hydroxytyrosol; (3) tyrosol; (4) 5-O-caffeoylquinic acid; (6) verbascoside; (7) luteolin-7-O-glucoside; (8) rutin; (9) apigenin-7-O-glucoside; and (10) apigenin. Numbers correspond to the phenolic compounds presented in Fig. 1.

Greek commercial table olives, ${ }^{27}$ a lower quantity of olive pulp is needed to reach the $\mathrm{IC}_{50}$ values (DPPH method) in the Portuguese table olives, revealing higher antiradical potential.

When pure phenolic compounds were tested (hydroxytyrosol, tyrosol and verbascoside; Fig. 3 and Table 3), it was observed that the aqueous extracts of table olives were more active than tyrosol in both methods assayed. When we tested tyrosol in both antioxidant methods even at the highest concentration tested the $\mathrm{IC}_{50}$ value was not reached. Hydroxytyrosol revealed extremely high antioxidant activity, with $\mathrm{IC}_{50}$ values of 0.034 and $0.014 \mathrm{mg} \mathrm{mL}^{-1}$ respectively for reducing power and DPPH methods. Among the phenolic compounds tested, verbascoside reported intermediate antioxidant activity with $\mathrm{IC}_{50}$ values of 0.121 and $0.030 \mathrm{mg} \mathrm{mL}^{-1}$ respectively for reducing power and DPPH methods.

The antioxidant activity of the table olives is partially related with the phenolic composition of the extracts. In fact, when a regression analysis was established between the phenolic profile and total phenol content with the $\mathrm{IC}_{50}$ values of both antioxidant assays tested, correlations were established
(Table 4). 5-O-Caffeoylquinic acid was not correlated with the antioxidant activity displayed in both methods, as well as apigenin 7-O-glucoside in the DPPH method. The remaining phenolic compounds as well as total phenol content reported very significant or extremely significant correlations. The equations obtained from the regression analysis revealed negative slope values. In this case, a negative slope indicates that the higher the content of a determined phenolic compound, the lower are the $\mathrm{IC}_{50}$ values, which means a higher antioxidant activity.

In order to summarize the data obtained in the phenolic profile and the antioxidant activity of the 24 aqueous extracts of natural fermented table olives, a principal component analysis (PCA) was performed. $64.42 \%$ of the total variance of the data can be explained using two principal factors (Fig. 4). Samples were gathered into three main groups: one group is represented in the negative region of the first principal factor (samples 17, 21, 22 and 23); a second group is represented in the central region of the figure; and a third group composed only of sample 24 . Sample 24 is represented in both positive regions of the principal factors due its high values obtained in 
Table 3 Extraction yield and $\mathrm{IC}_{50}$ values $\left(\mathrm{mg} \mathrm{mL}^{-1}\right)$ of aqueous extracts of natural fermented table olives

\begin{tabular}{|c|c|c|c|c|c|}
\hline Sample & Extraction yield (\%) & Reducing power $\left(\mathrm{IC}_{50}{ }^{a}\right)$ & Olive pulp ${ }^{b}(\mathrm{mg})$ & $\mathrm{DPPH}\left(\mathrm{IC}_{50}{ }^{\mathrm{C}}\right)$ & Olive pulp ${ }^{d}(\mathrm{mg})$ \\
\hline 1 & $17.19 \pm 0.14$ & $0.91 \pm 0.07$ & $15.32 \pm 1.10$ & $0.16 \pm 0.00$ & $2.65 \pm 0.06$ \\
\hline 2 & $24.74 \pm 8.96$ & $1.33 \pm 0.13$ & $22.45 \pm 2.18$ & $0.53 \pm 0.06$ & $8.88 \pm 1.08$ \\
\hline 4 & $22.66 \pm 0.00$ & $0.63 \pm 0.01$ & $10.67 \pm 0.19$ & $0.44 \pm 0.00$ & $7.38 \pm 0.07$ \\
\hline 5 & $18.47 \pm 18.63$ & $0.79 \pm 0.05$ & $13.29 \pm 0.90$ & $0.42 \pm 0.01$ & $7.05 \pm 0.23$ \\
\hline 6 & $23.85 \pm 0.34$ & $1.26 \pm 0.12$ & $21.13 \pm 2.04$ & $0.47 \pm 0.07$ & $7.97 \pm 1.14$ \\
\hline 7 & $42.49 \pm 26.60$ & $1.46 \pm 0.08$ & $24.56 \pm 1.39$ & $0.68 \pm 0.03$ & $11.42 \pm 0.54$ \\
\hline 10 & $20.59 \pm 0.01$ & $0.71 \pm 0.05$ & $11.94 \pm 0.81$ & $0.28 \pm 0.01$ & $4.69 \pm 0.22$ \\
\hline 11 & $23.90 \pm 0.24$ & $1.30 \pm 0.04$ & $21.83 \pm 0.74$ & $0.75 \pm 0.03$ & $12.56 \pm 0.44$ \\
\hline 12 & $17.50 \pm 2.55$ & $0.80 \pm 0.09$ & $13.46 \pm 1.56$ & $0.42 \pm 0.04$ & $7.07 \pm 0.65$ \\
\hline 13 & $20.44 \pm 3.27$ & $1.46 \pm 0.10$ & $24.57 \pm 1.73$ & $0.72 \pm 0.06$ & $12.07 \pm 0.98$ \\
\hline 14 & $10.61 \pm 6.51$ & $0.49 \pm 0.08$ & $8.21 \pm 1.39$ & $0.22 \pm 0.06$ & $3.66 \pm 1.03$ \\
\hline 15 & $33.32 \pm 4.01$ & $1.59 \pm 0.03$ & $26.81 \pm 0.44$ & $0.72 \pm 0.06$ & $9.25 \pm 0.69$ \\
\hline 21 & $17.20 \pm 0.38$ & $0.41 \pm 0.02$ & $6.87 \pm 0.31$ & $0.18 \pm 0.01$ & $2.98 \pm 0.19$ \\
\hline 22 & $26.10 \pm 7.82$ & $0.30 \pm 0.01$ & $5.05 \pm 0.16$ & $0.13 \pm 0.00$ & $2.12 \pm 0.05$ \\
\hline 23 & $16.33 \pm 0.39$ & $0.34 \pm 0.03$ & $5.75 \pm 0.41$ & $0.16 \pm 0.00$ & $2.63 \pm 0.09$ \\
\hline 24 & $21.73 \pm 0.84$ & $2.67 \pm 0.11^{e}$ & $44.86 \pm 1.88^{f}$ & $1.85 \pm 0.29^{e}$ & $31.15 \pm 4.88^{g}$ \\
\hline \multicolumn{6}{|l|}{ Standards } \\
\hline Hydroxytyrosol & - & $0.034 \pm 0.000$ & - & $0.014 \pm 0.000$ & - \\
\hline Verbascoside & - & $0.121 \pm 0.001$ & - & $0.030 \pm 0.000$ & - \\
\hline
\end{tabular}

${ }^{a} \mathrm{IC}_{50}\left(\mathrm{mg} \mathrm{mL}^{-1}\right)$ : effective concentration at which the absorbance is $0.5{ }^{b}$ Quantity of fresh olive pulp necessary to reach the absorbance of 0.5 . ${ }^{c} \mathrm{IC}_{50}\left(\mathrm{mg} \mathrm{mL}^{-1}\right)$ : effective concentration at which $50 \%$ of DPPH radicals are scavenged. ${ }^{d}$ Quantity of fresh olive pulp necessary to scavenge $50 \%$ of the free radicals of DPPH. ${ }^{e} \mathrm{IC}_{25}$ value $\left(\mathrm{mg} \mathrm{mL} \mathrm{mL}^{-1}\right) .{ }^{f}$ Quantity of fresh olive pulp necessary to reach the absorbance of $0.25 .{ }^{g}$ Quantity of fresh olive pulp necessary to scavenge $25 \%$ of the free radicals of DPPH.
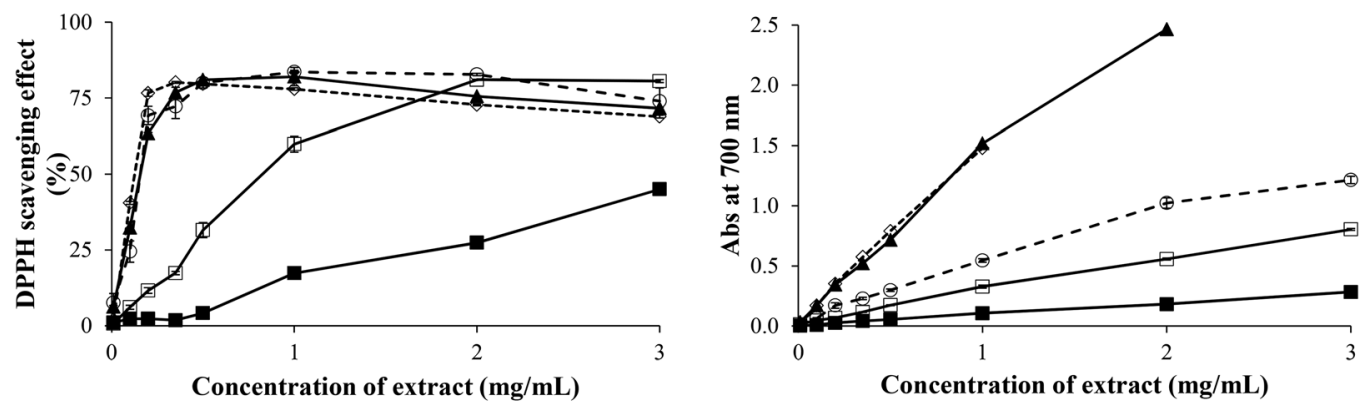

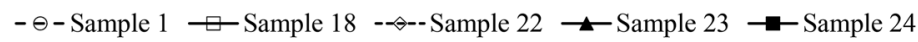
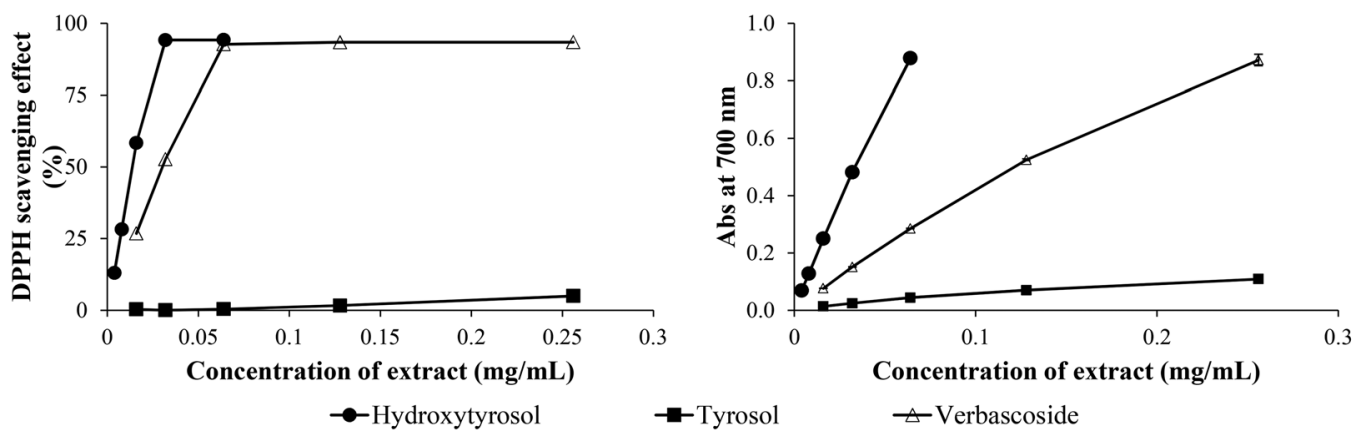

Fig. 3 Reducing power and DPPH scavenging effect of aqueous extracts of samples of natural fermented table olives and hydroxytyrosol, tyrosol and verbascoside (mean $\pm \mathrm{SE} ; n=2$ ). 
Table 4 Correlation between phenolic composition of natural fermented table olives and respective antioxidant activity

\begin{tabular}{|c|c|c|c|c|c|c|}
\hline Phenolic compound & \multicolumn{3}{|l|}{$\mathrm{IC}_{50} \mathrm{DPPH}$} & \multicolumn{3}{|l|}{$\mathrm{IC}_{50}$ reducing power } \\
\hline Hydroxytyrosol & $y=-0.025 x+0.727$ & 0.264 & $* * *$ & $y=-0.044 x+1.477$ & 0.345 & $* * *$ \\
\hline Tyrosol & $y=-0.053 x+0.577$ & 0.119 & ** & $y=-0.109 x+1.238$ & 0.208 & $* * *$ \\
\hline 5-O-Caffeoylquinic acid & $y=-0.196 x+0.493$ & 0.045 & n.s. & $y=-0.123 x+1.074$ & 0.005 & n.s. \\
\hline Verbascoside derivate & $y=-0.028 x+0.556$ & 0.178 & *** & $y=-0.059 x+1.202$ & 0.312 & $* * *$ \\
\hline Apigenin 7-O-glucoside & $y=-0.430 x+0.455$ & 0.109 & n.s. & $y=-1.463 x+1.183$ & 0.324 & ** \\
\hline Total phenols & $y=-0.011 x+0.714$ & 0.325 & $* * *$ & $y=-0.023 x+1.496$ & 0.513 & $* * *$ \\
\hline
\end{tabular}

n.s. - not significant; ${ }^{*} P \leq 0.05$ - significant correlation; ${ }^{* *} P \leq 0.01$ - very significant correlation; ${ }^{* *} P \leq 0.001$ - extremely significant correlation.

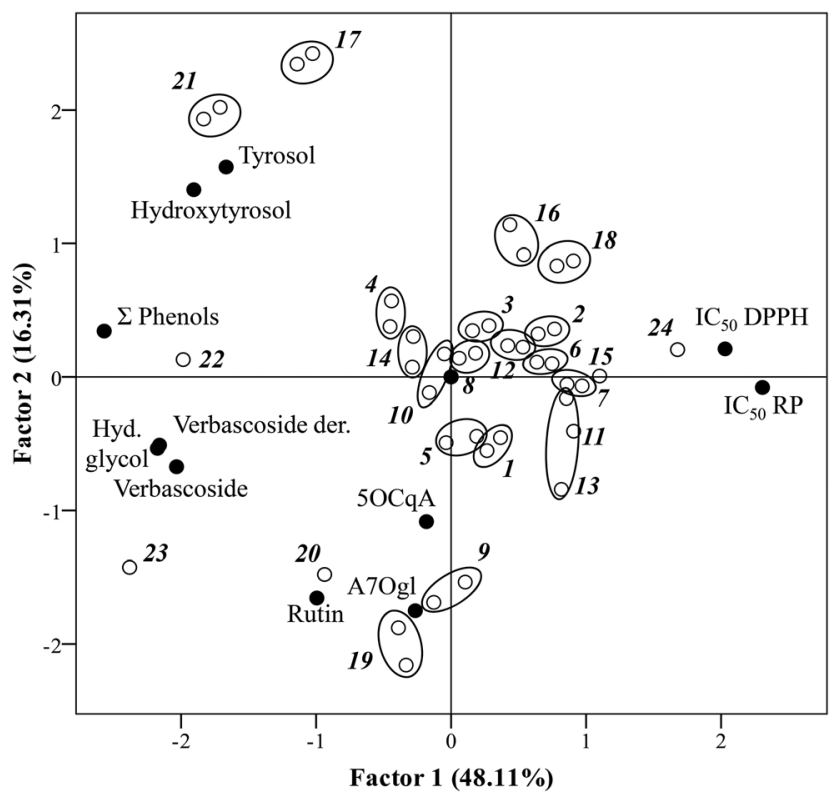

Fig. 4 Principal component analysis obtained from the phenolic composition and antioxidant activity recorded in the samples of natural fermented table olives. PCA factors explain $64.42 \%$ of the total variance. RP - reducing power; Hyd. glycol - hydroxytyrosol glycol; 50CqA 5-O-caffeoylquinic acid; A7Ogl - apigenin 7-O-glucoside.

the $\mathrm{IC}_{25}$, and is represented in the extreme opposite region of the first group because sample 24 was the one with lower total phenol content (Table 2). Samples 17, 21, 22 and 23 are represented in the negative region of the first principal factor because they are the samples with higher total phenol content and are those whose reported lower $\mathrm{IC}_{50}$ values correspond to the higher antioxidant activity. Even inside this group, samples 17 and 21 are represented in the positive region of the second principal factor due to being richer in hydroxytyrosol and tyrosol. On the other hand, samples 22 and 23 are separated from samples 17 and 21 because they are characterized by high content of hydroxytyrosol glycol, verbascoside and its derivate (Fig. 4). Therefore, the phenolic composition of the aqueous extracts is a critical aspect for the contribution of the antioxidant potential of the table olives.

\section{Antimicrobial activity of natural fermented table olives}

The antimicrobial activity was tested in the aqueous extracts of six table olive samples (samples 7, 8, 12, 13, 21 and 22). The choice of the samples to be tested was based on their antioxidant potential and extracts availability (Table 3). Samples 7 and 13 revealed, among the samples studied, the lowest antioxidant potential in both antioxidant chemical assays (sample 24 was not chosen due to extremely low performance). Samples 8 and 12 reported an intermediate antioxidant potential, while samples 21 and 22 were among those samples that exhibited an extraordinarily high antioxidant capacity.

The antimicrobial assays were tested against four Grampositive bacteria (B. cereus, B. subtilis, S. aureus, and S. epidermidis) and two Gram-negative bacteria ( $E$. coli and P. aeruginosa). The minimal inhibitory concentration (MIC) values for the tested bacteria were determined to evaluate the antimicrobial potential of the aqueous extracts of table olive samples and are reported in Table 5. The extracts revealed antimicrobial activity against all the microorganisms tested (except some extracts in E. coli) in a dose-dependent manner for each microorganism and according to the extract assayed. The results obtained revealed that Gram-positive bacteria were more susceptible to the table olive extracts. For the Bacillus genus, MIC varied between 12.5 and $25 \mathrm{mg} \mathrm{mL}^{-1}$ for B. subtilis and 12.5 and $50 \mathrm{mg} \mathrm{mL} \mathrm{m}^{-1}$ for $B$. cereus. Higher growth inhibition for both bacteria was observed in samples 8, 21 and 22 (MIC of $12.5 \mathrm{mg} \mathrm{mL}^{-1}$ ). On the other hand, samples 7 and 13 reported lower inhibition growth at higher concentrations (25 and $50 \mathrm{mg} \mathrm{mL}^{-1}$, respectively, for B. subtilis and B. cereus) compared with the remaining extracts. Concerning the Staphylococcus genus, generally, the bacteria tested were more resistant than Bacillus. Among Staphylococcus, S. aureus was more inhibited than $S$. epidermidis. For $S$. aureus, sample 21 reported good inhibition growth at $12.5 \mathrm{mg} \mathrm{mL}^{-1}$, followed by samples 22 and $8\left(25 \mathrm{mg} \mathrm{mL}^{-1}\right)$, and finally sample 7 reported lower inhibition growth at $50 \mathrm{mg} \mathrm{mL}$, the same pattern observed for the Bacillus genus bacteria. Meanwhile, the results obtained in $S$. epidermidis revealed high MIC values, $50 \mathrm{mg} \mathrm{mL} \mathrm{m}^{-1}$, sample 8 reporting higher inhibition at this con- 
Table 5 Antimicrobial activity of the samples tested of natural fermented table olives. Results are expressed as MIC (minimum inhibitory concentration; $\left.\mathrm{mg} \mathrm{mL}^{-1}\right)^{a}$

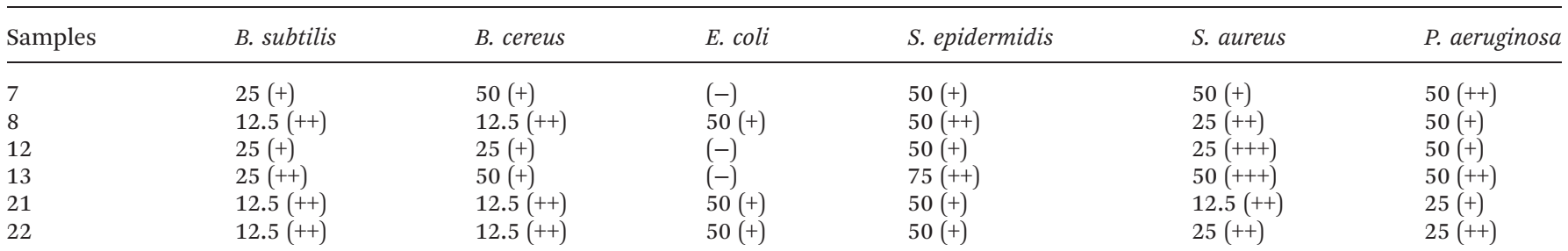

${ }^{a}(-)$ Inhibition zone $<1 \mathrm{~mm}$; slight antimicrobial activity $(+)$ inhibition zone $2-3 \mathrm{~mm}$; moderate antimicrobial activity (++) inhibition zone 4-5 $\mathrm{mm}$; high antimicrobial activity $(+++)$ inhibition zone $6-9 \mathrm{~mm}$; standard deviation $\pm 0.5 \mathrm{~mm}$.

centration. In this bacteria, sample 13 reported lower inhibition, with an MIC value of $75 \mathrm{mg} \mathrm{mL}^{-1}$.

When we studied Gram-negative bacteria, the differences among table olive extracts were even more notorious (Table 5). Pseudomonas aeruginosa was more inhibited by samples 21 and 22, with MIC values of $25 \mathrm{mg} \mathrm{mL}^{-1}$, sample 22 reporting higher inhibition growth. Surprisingly, samples 7 and 13 inhibited more $P$. aeruginosa growth than samples 8 and 12, but with the same MIC value $\left(50 \mathrm{mg} \mathrm{mL}^{-1}\right)$. Escherichia coli were the most resistant bacteria among all tested. Only samples 8, 21 and 22 were capable of inhibiting these bacteria at an MIC value of $50 \mathrm{mg} \mathrm{mL}{ }^{-1}$. Samples 7, 12 and 13 even at $100 \mathrm{mg} \mathrm{mL}{ }^{-1}$ (maximum concentration tested) were unable to inhibit the bacterial growth.

The results obtained are mainly related to two crucial aspects: (i) the microorganisms tested and (ii) extract composition. Gram-positive bacteria were more susceptible than Gram-negative bacteria, a result in agreement with several studies on the antimicrobial potential of different plant extracts $^{28-31}$ and table olives. ${ }^{11,32}$ This fact is related with the bacterial cell wall structure. Gram-negative bacteria possess an outer-membrane composed of lipopolysaccharides ${ }^{33}$ that protect the microorganisms acting as a permeability barrier, enabling the antimicrobial agents to enter the bacterial cell, ${ }^{34}$ a fact not shared by Gram-positive microorganisms. On the other hand, the extracts that exhibited higher antimicrobial potential reported medium-high antioxidant activity, with total phenol content above $50 \mu \mathrm{g} \mathrm{mg}^{-1}$ of extract (samples 21 and 22). As observed in the results of antioxidant activity, the antimicrobial activity of the aqueous extracts is related with the phenolic composition. In fact, the antimicrobial capacity of phenolic compounds is well known..$^{7,35,36}$ Thus, in order to assess the possible role of the major phenolic compounds in aqueous extracts, hydroxytyrosol, tyrosol and verbascoside were also tested for their antimicrobial activity. Little antimicrobial capacity was observed for these individual and isolated compounds (data not shown). Such results could be related with their individuality, since, according to Borchers et al., ${ }^{37}$ extracts may possess higher bioactivity than isolated compounds, because a bioactive individual component can change its properties in the presence of other compounds in the extract, increasing the overall bioactivity displayed.
Comparatively to other table olives, the antimicrobial potential of the aqueous extracts of natural fermented table olives is similar to that presented by "alcaparras" table olives, ${ }^{32}$ a particular kind of stoned table olives produced in Trás-os-Montes (northeast of Portugal). However our results revealed higher bioactivity than table olives from Trás-osMontes produced by several technological processes. ${ }^{11}$

\section{Experimental}

\section{Standards and reagents}

Methanol, 2,2-diphenyl-1-picrylhydrazyl, iron(III) chloride, and agar-agar were obtained from Sigma-Aldrich (St. Louis, USA). Methanol (HPLC grade), sodium dihydrogen phosphate dihydrate, potassium hexacyanoferrate(III), formic acid 98-100\%, and glucose were purchased from Merck (Darmstadt, Germany). Hydrochloric acid, sodium chloride, and di-sodium hydrogen phosphate 2-hydrate were obtained from Panreac (Barcelona, Spain). The standards used for phenolic profile identification were obtained from Sigma (St. Louis, USA) and Extrasynthèse (Genay, France). Yeast extract, peptone and tryptone were obtained from Himedia (Mumbai, India). The water was treated in a Milli-Q water purification system (Millipore, Bedford, MA, USA).

\section{Table olive sampling}

Twenty-four samples of natural fermented table olives were collected directly from producers of the Trás-os-Montes region (Table 1). A sample of $2 \mathrm{~kg}$ of olives was collected per producer, which were transported to the laboratory and frozen at $-20{ }^{\circ} \mathrm{C}$ until extraction and analysis.

\section{Preparation of the aqueous extracts}

For each sample the table olives were freeze-dried at $-110{ }^{\circ} \mathrm{C}$ (CoolSafe 110-4 Scanvac, LaboGene, Lynge, Denmark). After freeze-drying, samples were mashed and two sub-samples were constituted, which were subjected to an aqueous extraction as described by Sousa et al. ${ }^{32}$ and Malheiro et al. ${ }^{8}$ Briefly, $\approx 5 \mathrm{~g}$ of table olives (20 mesh) were extracted with $250 \mathrm{~mL}$ of boiling water for $45 \mathrm{~min}$ and filtered through Whatman no. 4 paper. The obtained aqueous solutions were frozen and freeze-dried in order to obtain the aqueous extracts. The extracts were then 
dissolved in water at concentrations ranging from 0.01 to $5 \mathrm{mg}$ $\mathrm{mL}^{-1}$ for antioxidant activity assays, $50 \mathrm{mg} \mathrm{mL} \mathrm{mL}^{-1}$ for phenolic profile evaluation, and between 12.5 and $100 \mathrm{mg} \mathrm{mL}^{-1}$ for antimicrobial activity.

\section{Phenolic compound analysis}

For identification and quantification purposes of the phenolic compounds of the natural fermented table olives, each lyophilized aqueous extract was redissolved in water, filtered $(0.2 \mu \mathrm{m}$ nylon membrane (Whatman)) and $20 \mu \mathrm{L}$ were injected into an analytical HPLC Knauer Smartline separation module equipped with a Knauer Smartline autosampler 3800, a cooling system set to $4{ }^{\circ} \mathrm{C}$ and a Knauer Diode Array Detector (DAD). A reversed-phase Spherisorb ODS2 column was used $(250 \times 4 \mathrm{~mm}$ id, $5 \mu \mathrm{m}$ particle diameter, end-capped Nucleosil $\mathrm{C} 18$ (Macherey-Nagel)) maintained at $30^{\circ} \mathrm{C}$. Chromatographic separation was carried out as reported previously ${ }^{9}$ using a gradient that consisted of solvent A (water-formic acid (19:1)) and solvent B (methanol), applied at a flow rate of $0.9 \mathrm{~mL}$ $\min ^{-1}$, as follows: $5 \% \mathrm{~B}$ at $0 \mathrm{~min}, 15 \% \mathrm{~B}$ at $3 \mathrm{~min}, 25 \% \mathrm{~B}$ at $13 \mathrm{~min}, 30 \% \mathrm{~B}$ at $25 \mathrm{~min}, 35 \% \mathrm{~B}$ at $35 \mathrm{~min}, 40 \% \mathrm{~B}$ at $39 \mathrm{~min}$, $45 \% \mathrm{~B}$ at $42 \mathrm{~min}, 45 \% \mathrm{~B}$ at $45 \mathrm{~min}, 47 \% \mathrm{~B}$ at $50 \mathrm{~min}, 48 \% \mathrm{~B}$ at $60 \mathrm{~min}, 50 \% \mathrm{~B}$ at $64 \mathrm{~min}$ and $100 \% \mathrm{~B}$ at $66 \mathrm{~min}$. Detection was achieved with a DAD. Spectral data from all peaks were accumulated in the range $200-600 \mathrm{~nm}$, and chromatograms were recorded at 280, 320, $330 \mathrm{~nm}$ and $350 \mathrm{~nm}$. Data acquisition and remote control of the HPLC system were done using the ClarityChrom ${ }^{\circledR}$ software (Knauer, Berlin, Germany). The compounds in each extract were identified by comparing their retention times and UV-Vis spectra in the 200-600 $\mathrm{nm}$ range with authentic standards analyzed under the same conditions and with the library of spectra previously compiled by the authors. The peak purity was checked by the software contrast facilities.

Phenolic compounds quantification was achieved by the absorbance recorded in the chromatograms relative to external standards. Hydroxytyrosol glycol, hydroxytyrosol and tyrosol were determined at $280 \mathrm{~nm}, 5$-O-caffeoylquinic acid at $320 \mathrm{~nm}$, verbascoside derivative and verbascoside at $330 \mathrm{~nm}$ and all the other compounds at $350 \mathrm{~nm}$. Hydroxytyrosol glycol was quantified as hydroxytyrosol. 5-O-caffeoylquinic acid was quantified as chlorogenic acid. Verbascoside derivative was quantified as verbascoside. The remaining compounds were quantified as themselves.

\section{Antioxidant activity}

Reducing power assay. Reducing power was determined according to a previously described procedure. ${ }^{38}$ Various concentrations (from 0.01 to $5 \mathrm{mg} \mathrm{mL}^{-1}$ ) of sample extracts $(1 \mathrm{~mL}$ ) were mixed with $2.5 \mathrm{~mL}$ of $200 \mathrm{mmol} \mathrm{L}^{-1}$ sodium phosphate buffer (pH 6.6) and $2.5 \mathrm{~mL}$ of $1 \%$ potassium ferricyanide. The mixture was shaken vigorously and then incubated at $50{ }^{\circ} \mathrm{C}$ for $20 \mathrm{~min}$. After incubation, $2.5 \mathrm{~mL}$ of $10 \%$ trichloroacetic acid $(\mathrm{w} / \mathrm{v})$ was added and then the mixture was centrifuged at 1000 $\mathrm{rpm}$ in a refrigerated centrifuge (Centorion K24OR-2003, $4{ }^{\circ} \mathrm{C}$ ) for $8 \mathrm{~min}$. The upper layer $(2.5 \mathrm{~mL})$ was mixed with $2.5 \mathrm{~mL}$ of deionized water and $0.5 \mathrm{~mL}$ of $0.1 \%$ ferric chloride. The absorbance was measured spectrophotometrically at $700 \mathrm{~nm}$. The extract concentration providing 0.5 of absorbance $\left(\mathrm{IC}_{50}\right)$ was calculated from the graph of absorbance registered at $700 \mathrm{~nm}$ against the corresponding extract concentration. The experiments were performed in triplicate per extract.

DPPH radical scavenging effect. The ability to scavenge the 2,2-diphenyl-1-picrylhydrazyl (DPPH) free radical was monitored according to the method reported by Malheiro et al. ${ }^{8}$ Various concentrations (from 0.01 to $5 \mathrm{mg} \mathrm{mL} \mathrm{m}^{-1}$ ) of sample extracts $(0.3 \mathrm{~mL})$ were mixed with $2.7 \mathrm{~mL}$ of methanolic solution containing DPPH radicals $\left(6 \times 10^{-5} \mathrm{~mol} \mathrm{~L}^{-1}\right)$. The mixture was shaken vigorously and left to stand in the dark at room temperature until stable absorption values at $517 \mathrm{~nm}$ were obtained (60 $\mathrm{min})$. The DPPH radical scavenging effect was calculated as the percentage of DPPH discoloration using the following equation:

$$
\begin{aligned}
& \% \text { DPPH radical scavenging capacity } \\
& \quad=\left[\left(A_{\mathrm{DPPH}}-A_{\mathrm{S}}\right) / A_{\mathrm{DPPH}}\right] \times 100
\end{aligned}
$$

where $A_{\mathrm{S}}$ is the absorbance of the solution when the sample extract was added and $A_{\mathrm{DPPH}}$ is the absorbance of the DPPH solution. The extract concentration providing $50 \%$ inhibition $\left(\mathrm{IC}_{50}\right)$ was calculated from the graph of scavenging effect percentage against the extract concentration. The experiments were performed in triplicate per extract.

\section{Antimicrobial activity}

For the antimicrobial activity assays, 6 table olive samples (7, $8,12,13,21$ and 22) were selected according to their availability and the results obtained in the preliminary antioxidant chemical assays.

\section{Microorganisms and culture conditions}

Four Gram-positive (Bacillus cereus, Bacillus subtilis, Staphylococcus aureus and Staphylococcus epidermidis) and two Gramnegative (Escherichia coli and Pseudomonas aeruginosa) bacterial strains were used. All the microorganisms were obtained from the Biology Department of University of Minho (Braga, Portugal). Bacterial stock cultures were maintained at $4{ }^{\circ} \mathrm{C}$ on LB agar [tryptone 1\% (w/v), $\mathrm{NaCl} 1 \%(\mathrm{w} / \mathrm{v})$ and agar $2 \%(\mathrm{w} / \mathrm{v})$ ], being sub-cultured periodically at $37^{\circ} \mathrm{C}$.

\section{Preliminary assays for antimicrobial activity}

The screening for natural fermented olive activities against Gram-positive and Gram-negative bacteria as well as the determination of the minimal inhibitory concentration (MIC) values was achieved by an adaptation of the agar streak dilution method based on radial diffusion. ${ }^{39}$ Suspensions of the microorganisms were prepared and mixed with molten agar $(0.8 \%, \mathrm{w} / \mathrm{v})$ in order to contain approximately $10^{6} \mathrm{cfu}$ $\mathrm{mL}^{-1}$. A volume of $8 \mathrm{~mL}$ of this mixture was seeded as a lawn onto the surface of plates containing the LB assay medium for bacteria. Samples to be tested for antimicrobial potential were placed $(85 \mu \mathrm{L})$ in a hole made in the center of the solid 
medium ( $3 \mathrm{~mm}$ depth, $5 \mathrm{~mm}$ diameter). The MIC was considered to be the lowest concentration of the tested sample $\left(12.5,25,50,75\right.$ and $\left.100 \mathrm{mg} \mathrm{mL}^{-1}\right)$ that is able to inhibit the growth of bacteria (after $24 \mathrm{~h}$ at $37^{\circ} \mathrm{C}$ ). The diameters of the inhibition zones were measured using a ruler, with an accuracy of $0.5 \mathrm{~mm}$. Each inhibition zone diameter was measured three times (in three different plates) and the results were expressed as the average of the radii of the inhibition zone in $\mathrm{mm}$. Plates inoculated with each sensitive indicator microorganism were used as controls.

\section{Statistical analysis}

Linear regression analysis. A regression analysis, using Excel from Microsoft Corporation, was established between the individual phenolics identified as well as for total phenol content of the twenty-four samples of natural fermented table olives with the $\mathrm{IC}_{50}$ values obtained in both the antioxidant chemical assays tested (DPPH and reducing power).

Principal component analysis. Principal components analysis (PCA) was applied for reducing the number of variables (hydroxytyrosol glycol, hydroxytyrosol, tyrosol, 5-O-caffeoylquinic acid, verbascoside derivate, verbascoside, rutin, apigenin 7-O-glucoside, total phenols content, and $\mathrm{IC}_{50}$ values obtained in both antioxidant assays tested) to a smaller number of the new derived variables (principal component or factors) that adequately summarize the original information, i.e., the phenolic composition and antioxidant potential of 24 samples of natural fermented table olives. Moreover, it allowed recognizing patterns in the data by plotting them in a multidimensional space, using the new derived variables as dimensions (factor scores).

The aim of the PCA is to produce components suitable to be used as predictors or response variables in a subsequent analysis. The number of factors to keep in data treatment was evaluated by the Scree plot, taking into account the eigenvalues, which should have: values greater than one for retaining the factor in the analysis, high values of total percentage of variance explained by the number of components selected for internal consistency by means of $\alpha$-Cronbach's value which should be positive. ${ }^{40}$

\section{Conclusions}

Natural fermented table olives from Trás-os-Montes were revealed to possess phenolic compounds with bioactive properties. The antioxidant activity of the table olive aqueous extracts was directly related to their phenolic composition. The same was verified for the antimicrobial potential. Table olives with high phenolic content and high antioxidant activity displayed higher microbial growth inhibition. Such results highlight the importance of the consumption of natural fermented table olives, this product being capable of preventing diseases in which free radicals are involved as well as to inhibiting the growth of the most common microorganisms.

\section{Acknowledgements}

This work was supported by project SUB-IOC-TEC 11/12 “Table olives from the Northeast of Portugal: Contribution for their characterization and promotion".

\section{References}

1 International Olive Council (IOC) World Table Olives Figures - Consumption. 2013. Available at: http://www. internationaloliveoil.org/estaticos/view/132-world-table-olivefigures (accessed June 2014).

2 G. Blekas, C. Vassilakis, C. Harizanis, M. Tsimidou and D. G. Boskou, J. Agric. Food Chem., 2002, 50, 3688-3692.

3 A. López-López, A. Montaño, M. V. Ruíz-Méndez and A. Garrido-Fernández, J. Am. Oil Chem. Soc., 2008, 85, 253-262.

4 F. Sakouhi, S. Harrabi, C. Absalon, K. Sbei, S. Boukhchina and H. Kallel, Food Chem., 2008, 108, 833-839.

5 J. M. Amiot, A. Fleuriet and J. J. Macheix, J. Agric. Food Chem., 1986, 34, 823-826.

6 F. Visioli, A. Poli and C. Gall, Med. Res. Rev., 2002, 22, 65-75.

7 G. Bisignano, A. Tomaino, R. L. Cascio, G. Crisafi, N. Uccella and A. Saija, J. Pharm. Pharmacol., 1999, 51, 971-974.

8 R. Malheiro, A. Sousa, S. Casal, A. Bento and J. A. Pereira, Food Chem. Toxicol., 2011, 49, 450-467.

9 A. F. Vinha, F. Ferreres, M. S. Silva, P. Valentão, A. Gonçalves, J. A. Pereira, M. B. Oliveira, R. M. Seabra and P. B. Andrade, Food Chem., 2005, 89, 561-568.

10 J.-R. Morelló, M.-P. Romero and M.-J. Motilva, J. Agric. Food Chem., 2004, 52, 6002-6009.

11 J. A. Pereira, A. P. G. Pereira, I. C. F. R. Ferreira, P. Valentão, P. B. Andrade, R. Seabra, L. Estevinho and A. Bento, J. Agric. Food Chem., 2006, 54, 8425-8431.

12 C. Romero, M. Brenes, K. Yousfi, P. García, A. García and A. Garrido, J. Agric. Food Chem., 2004, 52, 479-484.

13 S. Charoenprasert and A. Mitchell, J. Agric. Food Chem., 2012, 60, 7081-7095.

14 A. García, C. Romero, E. Medina, P. García, A. de Castro and M. Brenes, J. Agric. Food Chem., 2008, 56, 11862-11867.

15 M. H. Gordon, F. Paiva-Martins and M. Almeida, J. Agric. Food Chem., 2001, 49, 2480-2485.

16 Y. O’Dowd, F. Driss, P. M.-C. Dang, C. Elbim, M. A. Gougerot-Pocidalo, C. Pasquier and J. El-Benna, Biochem. Pharmacol., 2004, 68, 2003-2008.

17 M. González-Santiago, E. Martín-Bautista, J. J. Carrero, J. Fonollá, L. Baró, M. V. Bartolomé, P. Gil-Loyzaga and E. López-Huertas, Atherosclerosis, 2006, 188, 35-42.

18 C. L. Léger, M. A. Carbonneau, F. Michel, E. Mas, L. Monnier, J. P. Cristol and B. Descomps, Eur. J. Clin. Res., 2005, 59, 727-730.

19 C. Manna, V. Migliardi, F. Sannino, A. De Martino and R. Capasso, J. Agric. Food Chem., 2005, 53, 9602-9607. 
20 V. R. Gutierrez, R. de la Puerta and A. Catalá, Mol. Cell. Biochem., 2001, 217, 35-41.

21 R. Fabiani, A. De Bartolomeo, P. Rosignoli, M. Servili, G. F. Montedoro and G. Morozzi, Eur. J. Cancer Prev., 2002, 11, 351-358.

22 V. Marsilio, L. Seghetti, E. Iannucci, F. Russi, B. Lanza and M. Felicioni, J. Sci. Food Agric., 2005, 85, 1084-1090.

23 G. Rodríguez, A. Lama, S. Jaramillo, J. M. Fuentes-Alventosa, R. Guillén, A. Jiménez-Araujo, R. Rodríguez-Arcos and J. Fernández-Bolaños, J. Agric. Food Chem., 2009, 57, 62986304.

24 C. Romero and M. Brenes, J. Agric. Food Chem., 2012, 60, 9017-9022.

25 G. Rodríguez, J. Fernández-Bolaños, R. Rodríguez, R. Guillén and A. Jiménez, Eur. Food Res. Technol., 2007, 224, 733-741.

26 A. Sousa, I. C. F. R. Ferreira, L. Barros, A. Bento and J. A. Pereira, Food Sci. Technol., 2008, 41, 739-745.

27 G. Boskou, F. N. Salta, S. Chrysostomou, A. Mylona, A. Chiou and N. K. Andrikopoulos, Food Chem., 2006, 94, 558-564.

28 R. Malheiro, O. Sá, E. Pereira, C. Aguiar, P. Baptista and J. A. Pereira, Ind. Crops Prod., 2012, 37, 473-478.

29 C. Proestos, N. Chorianopoulos, G.-J. E. Nychas and M. Komaitis, J. Agric. Food Chem., 2005, 53, 1190-1195.
30 J. A. Pereira, I. Oliveira, A. Sousa, P. Valentão, P. B. Andrade, I. C. F. R. Ferreira, F. Ferreres, A. Bento, R. Seabra and L. Estevinho, Food Chem. Toxicol., 2007, 45, 2287-2295.

31 I. Oliveira, A. Sousa, I. C. F. R. Ferreira, A. Bento, L. Estevinho and J. A. Pereira, Food Chem. Toxicol., 2008, 45, 2326-2331.

32 A. Sousa, I. C. F. R. Ferreira, R. Calhelha, P. B. Andrade, P. Valentão, R. Seabra, L. Estevinho, A. Bento and J. A. Pereira, Bioorg. Med. Chem., 2006, 14, 8533-8538.

33 T. J. Beveridge, J. Bacteriol., 1999, 181, 4275-4733.

34 K. Poole, Curr. Opin. Microbiol., 2001, 4, 500-508.

35 T. P. T. Cushnie and A. J. Lamb, Int. J. Antimicrob. Agents, 2005, 26, 343-356.

36 G. Tunçel and C. Nergiz, Lett. Appl. Microbiol., 1993, 17, 300-302.

37 A. T. Borchers, C. L. Keen and M. E. Gerstiwin, Exp. Biol. Med., 2004, 229, 393-406.

38 K. Berker, K. Güçlü, I. Tor and R. Apak, Talanta, 2007, 72, 1157-1165.

39 Medical Bacteriology - A Practical Approach, ed. P. M. Hawkey and D. A. Lewis, Oxford University, 1994.

40 Methods of Multivariate Analysis, ed. A. C. Rencher, John Willey \& Sons, 1995. 